NBER WORKING PAPER SERIES

THE EVOLUTION OF IDEOLOGY, FAIRNESS AND REDISTRIBUTION

\author{
Alberto F. Alesina \\ Guido Cozzi \\ Noemi Mantovan \\ Working Paper 15587 \\ http://www.nber.org/papers/w15587
}

\author{
NATIONAL BUREAU OF ECONOMIC RESEARCH \\ 1050 Massachusetts Avenue \\ Cambridge, MA 02138
}

December 2009

The views expressed herein are those of the author(s) and do not necessarily reflect the views of the National Bureau of Economic Research.

NBER working papers are circulated for discussion and comment purposes. They have not been peerreviewed or been subject to the review by the NBER Board of Directors that accompanies official NBER publications.

(C) 2009 by Alberto F. Alesina, Guido Cozzi, and Noemi Mantovan. All rights reserved. Short sections of text, not to exceed two paragraphs, may be quoted without explicit permission provided that full credit, including $\odot$ notice, is given to the source. 
The Evolution of Ideology, Fairness and Redistribution

Alberto F. Alesina, Guido Cozzi, and Noemi Mantovan

NBER Working Paper No. 15587

December 2009

JEL No. H0,H1

\section{ABSTRACT}

Ideas about what is "fair" above and beyond the individual's position in the income ladder influence preferences for redistribution. We study the dynamic evolution of different economies in which redistributive policies, perceptions of fairness, inequality and growth are jointly determined. We show how including fairness explains various observed correlations between inequality, redistribution and growth. We also show how different beliefs about fairness can keep two otherwise identical countries in different development paths for a very long time.

\author{
Alberto F. Alesina \\ Department of Economics \\ Harvard University \\ Littauer Center 210 \\ Cambridge, MA 02138 \\ and NBER \\ aalesina@harvard.edu \\ Guido Cozzi \\ Durham University \\ guido.cozzi@durham.ac.uk
}

\author{
Noemi Mantovan \\ University of Glasgow \\ Economics Department \\ Adam Smith Building \\ Glasgow, G12 8RT \\ United Kingdom \\ n.mantovan.1@research.gla.ac.uk
}




\title{
The Evolution of Ideology, Fairness and Redistribution
}

\author{
Alberto Alesina*, Guido Cozzi ${ }^{\dagger}$ and Noemi Mantovan ${ }^{\ddagger}$
}

December 3, 2009

\begin{abstract}
Ideas about what is "fair" above and beyond the individuals' position in the income ladder influence preferences for redistribution. We study the dynamic evolution of different economies in which redistributive policies, perception of fairness, inequality and growth are jointly determined. We show how including fairness explains various observed correlations between inequality, redistribution and growth. We also show how different beliefs about fairness can keep two otherwise identical countries in different development paths for a very long time.
\end{abstract}

\section{Introduction}

The poor want to tax the rich, but that is not all what determines redistributive policies. Ideas about what is "fair" and about what is an acceptable level of inequality above and beyond the individuals' position in the income ladder also matter. ${ }^{1}$ The same level of inequality may be more or less acceptable by different individuals in different countries depending upon their beliefs that wealth has been accumulated with effort and ability rather than by luck, connections or even corruption. In one word whether different levels of income and wealth are "deserved" or not. ${ }^{2}$ These views about inequality and justice (which we may label "ideology") determine tax rates and the evolution of the distribution of income and wealth. But the latter itself generates changes in the proportion of wealth inequality due to effort or to other factors including luck and government intervention, thus changing individual views about redistribution.

*Harvard University and IGIER

${ }^{\dagger}$ Durham University

¥University of Glasgow

${ }^{1}$ See for instance the recent survey of preferences for redistribution by Alesina and Giuliano (2010) and the references cited therein. Alesina, Di Tella and McCulloch (2004) discuss different levels of inequality tolerance in various countries. Alesina and Glaeser (2004) focus on a comparison between Continental Europe and US. Persson and Tabellini (2000) provide an excellent overview of politico economic models of redistributive policies.

${ }^{2}$ See Fong (2001), Alesina and La Ferrara (2005) and Alesina and Giuliano (2010). 
In this paper we provide a politico economic model that can trace over time the evolution of polices (tax and transfer schemes), the evolution of inequality, and of the preferences for redistribution, as a function of changes in what individuals perceive as fair and unfair wealth differences. The introduction of concerns for fairness reconciles several empirical observations which would be inconsistent with models based upon individual income (and position in the income ladder) as the only determinant of the voters' views about taxes and transfers.

In our model different generations of voters are linked by bequests, thus redistributive policies in the past and past beliefs about what was fair influence the current generation's preferences. We are especially interested in two issues. One is how different initial conditions lead to long lasting differences in policies. The other one is how shocks to inequality imply different policy reactions. Regarding the first issue we study not only differences in the initial conditions of the economic system, but also, and perhaps more interestingly, differences in views about social justice and about the fairness of the inherited level of inequality. For instance two countries may be completely identical except for their views about the fairness of their initial inequality, and as a result they may adopt different redistributive policies over a long period of time which determines different wealth and inequality dynamics. These different patterns of taxation, inequality, and growth would be completely unexplainable without reference to initial views about what is fair or not, i. e. about social justice. These examples allow us to explain, for instance, different levels of redistribution between the US and Europe and their persistence along the lines of Alesina and Glaeser (2004) who stressed, informally, the role of the perception of poverty as an explanation of US versus Europe. We also show that for some parameter values economies with different initial beliefs but otherwise identical converge slowly to the same steady state. But for other parameter values identical economies but with different initial beliefs converge to two different steady states, thus their differences persist forever. Another implication of our model is that, contrary to standard result from the Meltzer and Richard's (1981) model, more inequality may be associated with less redistribution. This is because different levels of measured inequality may be considered more or less fair. ${ }^{3}$.

The second set of results concerns the effect of shocks to wealth inequality like those generated by wars (Piketty and Saez, 2003) or possibly the 2007-2009 financial crisis. Sudden exogenous shocks to inequality may generate very different policy reactions depending on the perception of individuals about who lost and who gained, namely if those who lost were those who were rich because of "luck" (broadly defined) or were those who had become rich because of effort and ability. Thus the same changes in inequality may have different effects on redistributive policies depending on the nature of how these shocks are perceived. An innovative feature of our model is that we can trace not only the evolution of wealth, inequality, and redistributive policies, but also of the

\footnotetext{
${ }^{3}$ See in fact Perotti (1996) and Bénabou (1996) for empirical evidence regarding this relationship.
} 
views about "fairness" in society, that is we can measure how much of the total inequality is considered fair at different points in time. We can also examine the effects of changes on people's views about fairness.

This paper is related to the work of Alesina and Angeletos (2005a,b) but it is richer in its dynamic dimension and it uses a different voting mechanism. We adopt as our benchmark the same definition of fairness as theirs, but we also analyze different definitions and we emphasize the transition to the steady state, which may take a long time. Also, unlike those authors who use a median voter model, we adopt a probabilistic voting framework, which is a more flexible tool to analyze various types of distribution of political influence. The influence of beliefs about effort as a determinant of redistributive policies has been analyzed in a different context by Bénabou and Tirole (2006). In their paper, beliefs are not shaped only by actual data, but also by agents' targets and psychological needs. ${ }^{4}$

The present paper is organized as follows. Section 2 describes the model: both the economy and the political aspects of it, and the equilibrium. Section 3 illustrates the dynamic evolution of the model and performs several experiments. The last section concludes. The Matlab codes used in the present paper are available from the authors upon request.

\section{The economy}

We have non overlapping generations of individuals, indexed by $t$. Population is constant, there is one active individual per-family, and the total mass of families is normalized to one. Each individual, indexed by $i \in[0,1]$, lives for one period and is characterized by a certain degree of endurance to effort, $\beta_{i}>0$, luck, $\eta_{i} \in R$, and inner abilities, $A_{i}>0$; average luck is zero, that is $\int_{0}^{1} \eta_{i} d i=0$. These family-specific variables are assumed, for now, fully persistent over time. In an extension below we also allow for non persistent luck. Each individual $i$ cares about consumption, $c_{i t}$, and how much wealth to bequeath to the next generation, $k_{i t}$ - which we label "capital" - and negatively on his effort, $e_{i t}$, on the job. All choice variables are constrained to be non-negative. The private utility function is:

$$
u_{i t}=\frac{1}{(1-\alpha)^{1-\alpha} \alpha^{\alpha}} c_{i t}^{1-\alpha} k_{i t}^{\alpha}-\frac{1}{2 \beta_{i}} e_{i t}^{2},
$$

$0<\alpha<1$. The final life gross wealth is:

$$
z_{i t}=A_{i} e_{i t}+\eta_{i}+k_{i t-1} .
$$

\footnotetext{
${ }^{4}$ In the present paper beliefs are consistent with reality. The fact that past experiences and views about history affect beliefs is consistent with Piketty (1995) who analyzes the dependence of the redistributive preferences on past income.
} 
For simplicity, initial capital is assumed to yield no returnt. Each generation votes on the tax rate, $\tau_{t}$, which is proportionally applied to end-of-life gross wealth $z_{i t}$; all tax revenues are to be redistributed lump sum to all individuals. Hence, we denote final life post-tax and transfer wealth as:

$$
w_{i t}=\left(1-\tau_{t}\right) z_{i t}+G_{t},
$$

where $G_{t}=\tau_{t} \int_{0}^{1} z_{i t} d i$ is the percapita transfer. The government budget is always balanced. Notice that in our stylized economy, individual income is $y_{i t}=\left(A_{i} e_{i t}+\eta_{i}\right)\left(1-\tau_{t}\right)-\tau_{t} k_{i t-1}+G_{t}$, and the aggregate income of generation $t$ is

$$
Y_{t}=\int_{0}^{1}\left[\left(A_{i} e_{i t}+\eta_{i}\right)\left(1-\tau_{t}\right)-\tau_{t} k_{i t-1}+G_{t}\right] d i=\int_{0}^{1} A_{i} e_{i t} d i,
$$

which is identical to percapita income due to the population normalization. While in principle we allow for a negative individual income ${ }^{5}$, in none of our simulations individuals can have negative wealth.

This warm glow intergenerational altruism implies that fraction $\alpha$ of end of life wealth is bequeathed, as seen by maximizing $u_{i t}$ subject to $c_{i t}+k_{i t}=w_{i t}$. Therefore, plugging the optimal consumption and bequest into the private utility function, we obtain:

$$
u_{i t}=w_{i t}-\frac{e_{i t}^{2}}{2 \beta_{i}} .
$$

Individuals vote on taxation at the beginning of life, before deciding on effort. Maximizing $u_{i t}$, using (3), (1), and (2), gives

$$
e_{i t}=\left(1-\tau_{t}\right) A_{i} \beta_{i},
$$

which shows that individual effort gets discouraged by expected taxation, and is increasing in the individual work ability and decreasing in the disutility of effort ${ }^{6}$.

The definition of a period needs discussion. In the model the period is one generation and it is also the length of time for which the redistributive policy cannot be changed. We solve the model below by computational methods and not in closed form. Therefore it would be relatively straightforward to allow many periods within one generation and allow for a vote on a tax rate in every period, so many votes and possibly many tax changes within one generation. However this complication would make the interpretation of the simulations heavier without adding much to the basic message of the paper. In addition, the

\footnotetext{
${ }^{5}$ In case an unlucky individual (i.e. some one with $\eta_{i}<0$ ) exherts zero effort, and redistribution does not help enough.

${ }^{6}$ As in Heckman (2008), we could distinguish between cognitive abilities (here summarized by $\left.A_{i}\right)$ and non-cognitive abilities $\left(1 / \beta_{i}\right)$.
} 
choice of a "tax rate" should not be interpreted as the day to day or year to year changes in fiscal policy, but the broad redistributive stand of a certain period in a certain country. For instance more redistribution in the US with the Great Society in the Sixties, or with the New Deal in the Thirties, less redistribution starting with Reagan in the Eighties and what followed. In Europe an increase in redistribution at the end of the Sixties, possibly a slowing down today etc.

\subsection{Inequality and fairness}

In addition to the standard utility function described above, we postulate that utility also depends negatively on some measure of inequality, i.e of wealth dispersion in society. In our benchmark case, as in Alesina and Angeletos (2005a) we posit that individuals tolerate inequality coming from innate ability and effort, but are averse to inequality arising from everything else, luck and redistribution.

More specifically, let us define "fair" utility and wealth as follows:

$$
\begin{aligned}
& \widehat{u}_{i t}=\widehat{w}_{i t}-\frac{e_{i t}^{2}}{2 \beta_{i}}, \\
& \widehat{w}_{i t}=A_{i} e_{i t}+\widehat{k}_{i t-1} .
\end{aligned}
$$

Remembering that each agent chooses $k_{i t}=\alpha w_{i t}$, where $\alpha$ represents the generosity towards the next generation, we define fair consumption, fair bequest, and fair disposable wealth as:

$$
\widehat{c}_{i t}=(1-\alpha) \widehat{z}_{i t} \quad \widehat{k}_{i t}=\alpha \widehat{z}_{i t} \quad \widehat{z}_{i t}=\widehat{w}_{i t}=A_{i} e_{i t}+\widehat{k}_{i t-1} .
$$

The generation $t$ individual $i$ utility, $U_{i t}$, is defined as:

$$
U_{i t}=u_{i t}-\gamma \Omega_{t}
$$

where

$$
\Omega_{t}=\int_{0}^{1}\left(u_{j t}-\widehat{u}_{j t}\right)^{2} d j=\int_{0}^{1}\left(w_{j t}-\widehat{w}_{j t}\right)^{2} d j .
$$

and $\gamma>0$ is the parameter which measures the importance of unfairness for society. This representation of utility implies that individuals in society dislike deviations from a distribution of wealth/utility in which everybody gets only the benefits from effort and innate ability. Note that the difference between total wealth and fair wealth is due to luck and government intervention with taxes and transfers. The higher the tax rate, the lower the equilibrium choice of effort; therefore the larger is the percentage of individual income due to luck rather 
than effort ${ }^{7}$, and the larger the proportion of differences across individuals due to luck rather than effort. In addition, to the extent that government transfers are not included in the definition of fair luck because not due to effort, this is an additional channel through which higher taxes induce a higher proportion of wealth perceived as not fair over the fair portion.

\subsection{Alternative definitions of fairness}

In the numerical simulations of the model. First we consider the case in which tax and transfers are considered part of fair wealth. Second, we look at cases in which the effect of $A_{i}$ is part of luck. One may argue that being born smart is part of a sort of genetically induced "luck". Alternatively one may argue that intelligence is fostered by growing up in a rich family with more child care and investment in education. Again this could be considered part of the endowment of an individual's luck at birth. Finally we consider the case in which individuals dislike inequality per se, namely any deviation of wealth and utility from equality for all at the average is costly. The latter would be an extreme definition of fairness in which any difference in wealth even if arising form harder work and more effort is unfair ${ }^{8}$. We will indeed compare the dynamic evolution of the economy under these different assumptions about tolerance for inequality and the definition of fairness.

\subsection{The polity}

We use a probabilistic voting model ${ }^{9}$. There are two parties - $L$, for "left", and $R$, for "right" - each of which simultaneously and credibly commits to a tax rate $\tau_{P} \in[0,1], P=L, R$, at the beginning of each period - coinciding with a generation. The individuals vote for a party at the beginning of their life. Then the individuals choose efforts. The party that obtained the majority of the votes is the only one in office, and it will apply the announced tax rate (to end of life wealths) and will redistribute accordingly. Finally, individuals choose their consumption and bequest.

Individuals have heterogeneous degrees of political party identification ${ }^{10}$ : the complete utility function including economic variables and party identification is the following:

$$
\tilde{U}_{i t P}=u_{i t}-\gamma \Omega_{t}+\left(\sigma_{i t}+\varepsilon_{t}\right) \chi_{L}(P), \text { where } P=L, R .
$$

Variable $P$ denotes the party that wins the election, and can take on values $L$ ( meaning "left") or $R$ ("right"). Indicator function $\chi_{L}(P)$ takes on value 1 if

\footnotetext{
${ }^{7}$ Notice that, for unlucky individuals, that percentage has opposite sign.

${ }^{8}$ Perhaps in the extreme one might argue that ability to tolerate fatigue is also part of someone's endowment of lucky features.

${ }^{9}$ Note that this voting model does not require single peakness of preferences and has other desirable properties. See Persson and Tabellini (2000) for an excellent presentation of it.

${ }^{10}$ Lindbeck and Weibull (1987 and 1993).
} 
$P=L$ and 0 if $P=R$. Random variable $\sigma_{i t}$ represents individual $i$ 's pro-party $L$ ideological bias, while $\varepsilon_{t}$ is an aggregate random variable capturing party $L$ 's popularity for generation $t$. While we assumed (for simplicity) that individuals' pecuniary utility and ability shocks are fully persistent across generations, that is $\beta_{i t}=\beta_{i}, \eta_{i t}=\eta_{i}$, and $A_{i t}=A_{i}$, political popularity may change from generation to generation both at the aggregate and at the family level. Each generation, $\varepsilon_{t}$ will be uniformly distributed on support $\left[-\frac{1}{2 \psi}, \frac{1}{2 \psi}\right]$, and individual specific variables $\sigma_{i t}$ are uniformly distributed on support $\left[-\frac{1}{2 \varphi_{i}}, \frac{1}{2 \varphi_{i}}\right]$. All random variables are independent. Therefore, in the support of the corresponding distrubutions, the density function of aggregate popularity of party $L$ is $\psi>0$, and family-specific density functions are $\varphi_{i}>0$, with the correlated (aggregate) component of the party identification assumed less variable than the individual components - that is $\psi>\varphi_{i}, \forall i \in[0,1]$. The two parties commit to their tax rates before they know the realization of the random variables $\varepsilon_{t}$ and $\sigma_{i t}$. They only care about winning the election, and hence choose their policies $\tau_{t}^{L}$ and $\tau_{t}^{R}$ by trying to maximize the probability of being elected, $p_{P}, P=L$, $R$. This is consistent with maximizing the expected rents from being in office ${ }^{11}$.

The "popularity shocks" should not be viewed as the day ebbs and flows of electoral politics. Given our definition of a period as one generation these shocks should be seen as long term switches of one generation to the left (say the sixties) or to the right, (say the eighties in the US).

\subsection{Equilibrium}

After simple substitutions, and momentarily neglecting the party $L$ bias components, we obtain the indirect utility function of each individual in each generation. That function ultimately depends on exogenous parameters, on expected taxation and on all the wealth distribution of the previous generation:

$$
\begin{aligned}
U_{i t} & =\left[\delta_{i}\left(1-\tau_{t}\right)+\eta_{i}+k_{i t-1}\right]\left(1-\tau_{t}\right)+\int_{0}^{1}\left[\delta_{j}\left(1-\tau_{t}\right) \tau_{t}+\tau_{t} k_{j t-1}\right] d j-\left(1-\tau_{t}\right)^{2} \frac{\delta_{i}}{2} \\
& -\gamma \int_{0}^{1}\left[\left(\delta_{s}\left(1-\tau_{t}\right)+\eta_{s}+k_{s t-1}\right)\left(1-\tau_{t}\right)+\int_{0}^{1}\left(\delta_{j}\left(1-\tau_{t}\right) \tau_{t}+\tau_{t} k_{j t-1}\right) d j-\delta_{s}\left(1-\tau_{t}\right)-\widehat{k}_{s t-1}\right]^{2} d s \\
& \equiv \hat{U}_{i t}\left(\tau_{t}\right) .
\end{aligned}
$$

\footnotetext{
${ }^{11}$ Let $\Pi^{P}>0$ denote the (non-transferable) ego rent of party $P=L, R$, from being in office, the expected rent of party $L$ will be $\Pi^{L} p_{L}=\Pi^{L}\left(1-p_{R}\right)$; whereas party $R$ maximizes $\Pi^{R} p_{R}=\Pi^{R}\left(1-p_{L}\right)$.
} 
Where $\delta_{i} \equiv A_{i}^{2} \beta_{i}$. It is straightforward to see that (the proof is in Appendix):

Lemma 1. In pairwise majority voting, there will exist a unique equilibrium in which the two parties will select the same policy variable, $\tau_{t}^{L}=\tau_{t}^{R} \equiv \tau_{t}^{*}$, given by

$$
\tau_{t}^{*}=\arg \max _{\tau_{t} \in[0,1]} \int_{0}^{1} \varphi_{i} \hat{U}_{i t}\left(\tau_{t}\right) d i .
$$

As in other probabilistic voting models, the same equilibrium policy variable would also be chosen by a biased social planner who maximized the following weighted aggregate welfare functional:

$$
W(\tau) \equiv \int_{0}^{1} \varphi_{i} \hat{U}_{i t}\left(\tau_{t}\right) d i,
$$

with each individual's indirect utility function (where effort, consumption, and bequest are all optimal) being weighted inversely to vulnerability, $1 / \varphi_{i}$, to partyrelated attributes. In the special case of individuals who have the same densities $\varphi_{i}=\varphi$, Lemma 1 implies that $\tau_{t}^{*}=\arg \max _{\tau_{t}} W\left(\tau_{t}\right)$ would coincide with the tax rate chosen by a social planner who adopts a utilitarian welfare functional. Notice that, from eq. (7), the equilibrium tax rate $\tau_{t}^{*}$ will depend on generation $t-1$ 's bequest distribution $k_{t-1}$, generation $t-1$ 's fair bequest distribution $\widehat{k}_{t-1}$, and of course on the parameter vectors $\delta$ and $\eta$; that is $\tau_{t}^{*}=\tau^{*}\left(k_{t-1}, \widehat{k}_{t-1}, \delta, \eta\right)$.

\subsection{Intergenerational Links}

The equilibrium tax rate $\tau_{t}^{*}$ determines the level of capital and fair capital for each family of the current generation. Therefore the link between different generations is summarized by the dynamics of $k_{i t}$ and $\widehat{k}_{i t}$ :

$$
\begin{gathered}
k_{i t}=\left[\delta_{i}\left(1-\tau_{t}\right)+\eta_{i}+k_{i t-1}\right]\left(1-\tau_{t}\right) \alpha+\alpha G_{t} \\
\widehat{k}_{i t}=\alpha \delta_{i}\left(1-\tau_{t}\right)+\alpha \widehat{k}_{i t-1} .
\end{gathered}
$$

Based on these dynamic equations, we notice that the distribution of $\delta_{i}$ should be high enough relative to the support of the distribution of $\eta_{i}$ in order for final life wealth never to be negative ${ }^{12}$. In all our simulations, the relative importance of mere luck is never overwhelming, and hence the non-negative final life wealth constraint is never violated.

\footnotetext{
${ }^{12}$ See Lemma 2 in the Appendix for a sufficiency condition.
} 


\subsection{Discussion}

Note that in eq. (10), "fair" bequest - i.e. of fair initial wealth, over the generations - are obtained by removing from the parental end of life wealth, the effects of the "luck" variable, $\eta_{i}$, and of the taxes paid to and transfers received by the government. However, the indirect effect of tax rates on individual efforts is included in this definition of fairness. The reader may wonder why " $\left(1-\tau_{t}\right)$ " should enter the "fair wealth": after all, it is an individually rational response to the distortion induced by taxation, and indeed $e_{i t}=\left(1-\tau_{t}\right) A_{i} \beta_{i}$. If redistribution did not exist in the model, the individual would have exerted a first best effort level $e_{i t}^{F}=A_{i} \beta_{i}$. We have run simulations under such a different view of fairness, based on "potential" rather than actual efforts, without much change in the results about the dynamics of $k_{i t}$. By eq. (10), it simplifies the dynamics of $\widehat{k}_{i t}$, which would tend to $\frac{\alpha \delta_{i}}{1-\alpha}$. However, the results of our computations do not change qualitatively.

Another objection could be raised against purging additive luck $\eta_{i}$ rather than both luck and ability $A_{i}$. Formally, luck enters additively while ability as the marginal product of effort: both could be viewed as "gifts of nature". Replacing $A_{i}$ with $\bar{A}=\int_{0}^{1} A_{i} d i$ would both be reasonable and consistent at the macroeconomic level (fair value added $=$ actual value added). Using $\bar{A} e_{i t}=$ $\bar{A}\left(1-\tau_{t}\right) A_{i} \beta_{i}$ as the valued added component of the end-of-life wealth, however, would not change the qualitative results much, as actual individual ability, $A_{i}$, would still enter multiplicatively indirectly via optimal effort choice. Purging this effect too, in addition to neglecting macroeconomic consistency, would not change much $^{13}$.

\section{Intergenerational Dynamics}

Starting from an initial vector of actual and fair wealth levels, $\left(k_{i 0}, \hat{k}_{i 0}\right)_{i \in[0,1]}$, we can iterate the model and determine the intergenerational evolution of $\left(k_{i t}, \hat{k}_{i t}\right)_{i \in[0,1]}$ and $\tau_{t}^{*}$ for all $t \in N$. We use equations (7), problem (8), and eq.s (9) and (10), which, once iterated for an arbitrary number of generations, allows to calculate the sequence of equilibrium values of the endogenous variables of our dynamic economy for all parameter vectors, initial wealth distribution, and initial fair wealth distribution. By simulating the model for a sufficiently high number of generations, we can approximate the stable steady state value of the endogenous variables associated with each initial condition. The Matlab codes we have used to generate our examples are available upon request.

Generation $t$ 's pair of distributions $\left(k_{i t}, \hat{k}_{i t}\right)_{i \in[0,1]}$ describe the interaction of real and "ideal" variables at time $t$. More precisely, the comparison between how society currently is - the actual distribution $\left(k_{i t}\right)_{i \in[0,1]}$ - and how society

\footnotetext{
${ }^{13}$ Notice that, while in the previous case replacing $A_{i}$ with its expected value in the direct abilities reduced the variance of $\delta_{i}$ (due to the elimination of the quadratic exponent on abilities), eliminating the variance of $A_{i}$ completely could even increase the variance of $\delta_{i}$.
} 
thinks it "should be" - the fair distribution $\left(\hat{k}_{i t}\right)_{i \in[0,1]}$ - sets the goals of the political action; together with the method of political competition - i.e. pairwise majority voting - this describes the political ideology prevailing for generation $t$ in that economy. The resulting political equilibrium generates the evolution of $\left(k_{i t+1}, \hat{k}_{i t+1}\right)_{i \in[0,1]}$, and therefore the political ideology (i.e policy goals) prevailing in the next generation. Thus we trace the evolution of ideology, fairness and redistribution, as well as the aggregate GDP percapita. We focus our attention on the effects of:

1. different initial beliefs about the fair wealth distribution (sub-section 3.1).

2. different initial inequality (section 3.2).

3. alternative definitions of fairness (section 3.3).

4. different initial levels of aggregate wealth and poverty traps (section 3.4).

5. temporary shocks to wealth inequality (section 3.5).

\subsection{Different Initial Ideas about Social Justice}

As suggested by Alesina and Glaeser (2004), part of the long term differences in the welfare states in US and Europe can be explained by the interplay of initial conditions and ideas of fairness. A society where citizens believe that the observed cumulated wealth differences are derived from previous family luck will choose to redistribute more than a society in which voters think that the current capital accumulation depended on past efforts and talents. In Europe, preexisting forms of feudalism and wealth related to nobility differed from the US, where modern capitalism developed without a long previous history of privilege and class differences. In this section, we simulate the dynamics of two societies, characterized by identical real economic and personal characteristics, but with different initial ideas of the fair wealth distribution. In the first country, $A$, every individual of generation 0 believes that all the inequality is unfair, namely the initial wealth levels of their cohort should be equal to be fair. At the other extreme, the citizens of country $B$ are initially convinced that the prevailing capital distribution is exactly the fair one.

Considering Figure 1a below, two economies identical in all market fundamentals, including inequality, but that at some point in their history a generation is born and it judges differently the (same) prevailing wealth distribution. In fact, our "period zero" is simply the start of our period of interest, but, of course, a long history might have preceded the "initial generation" we are considering, which otherwise would have started with no initial capital. Therefore a different way of interpreting this results is this: all of the sudden in an unexpected matter a new generation is born with extremely egalitarian views, with a break of the past. Thus we study how a new egalitarian generation of individuals might affect the resulting political equilibrium and economic performance 
over the subsequent generations.
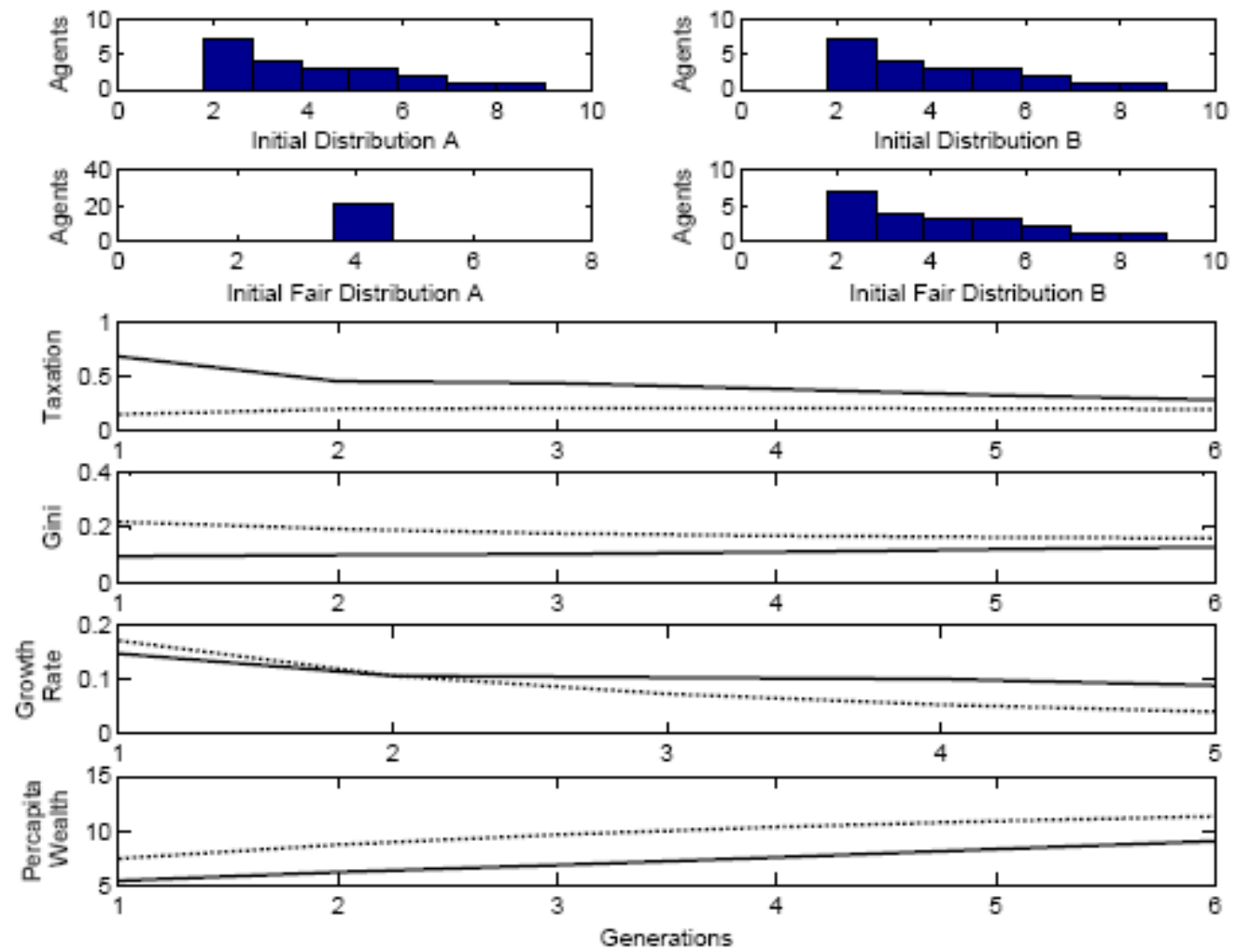

Figure 1a . Solid Line: Country A. Dashed Line: Country B

(11)

Figure 1a shows that, as a consequence of their perception of unfairness in the initial wealth distribution, country $A$ 's voters chose a high tax rate in period zero. This reduces inequality (even in the first period), but it also induces the successive generations to consider unfair the part of their inherited wealths stemming from the redistribution driven unearned changes in their predecessors' wealth. To correct the combined sources of unfairness still requires high taxes for a sufficiently long sequence of generations. Meanwhile, this does not take place in country $B$, where as a consequence work effort is higher and capital accumulation faster.

Individual preferences and the equilibrium tax rate (something we can name 
ideology) evolve from generation to generation. Consider country $A$. The first generation judges all inequality unfair; the second generation will believe their parents' ideal of their generation's fairness, but it will attribute part of the current pre-tax inequality to the efforts and abilities of their generation's members: therefore the desired tax rate will be lower. Incidentally note that the high tax rate chosen by the first generation in country $A$ will induce a relatively low choice of effort and work, and therefore the percentage of individual wealth due to luck is relatively high, thus the tax rate desired by generation 1 will still be relatively high. In country $B$ the first generation will not tax inequality because they perceived it as fair. Obviously the chosen tax rate will not be zero due to the need for correcting the effect of luck on unfairness within their cohort. But then the following generation will perceive that some of the inherited inequality is due to luck and therefore will choose to tax it. Unlike country $A$, since the initial tax rate was quite low much of the inequality within generation 1 will be due to effort, not luck, and therefore the chosen tax rate will not be much higher than in period zero. This shows that the two countries will remain rather different in terms of policy goals and tax/transfer redistributive schemes for many periods/generations. Initial conditions matter much. Policy goals (ideology) evolve over time together with the evolution of the economy, but initial differences in perception imply long lasting differences across countries.

More precisely, let us review the evolution of ideology implicit in eq. (10): $\widehat{k}_{i t}=\alpha \delta_{i}\left(1-\tau_{t}\right)+\alpha \widehat{k}_{i t-1}$. Individuals belonging to generation $t$ believe that every member of their cohort should bequeath a wealth level that reflects the bequest parental choice of a fraction, $\alpha$, of their end of life wealth; however that fraction should have been taken provided they earned the "fair" end-of-life wealth, given by $\widehat{z}_{i t}=\delta_{i}\left(1-\tau_{t}\right)+\widehat{k}_{i t-1}$. Thus individuals believe in the idea of fairness of their parents (as from the presence of " $+\widehat{k}_{i t-1}$ " in the formula); however, since the term " $\delta_{i}\left(1-\tau_{t}\right)$ " is just the equilibrium value of $A_{i} e_{i t}$, they also believe that the additional "fair" income of their peers should only arise from their individual efforts and productive abilities. Since, in turn, the effort chosen by the individual turns out to be equal to $e_{i t}=\left(1-\tau_{t}\right) A_{i} \beta_{i}$, its level will also reflect the individual's love for work, indeed represented by $\beta_{i}$. Thus the view of fair versus unfair inequality evolves from generation zero to generation 1 and this will imply different choices of tax rates and different bequests. The same considerations apply in the transition from generation 1 to 2 , and one can simulate the model forward to trace the transition to a steady state.

As shown in Figure 1b, we can keep track of the level of the variance of the wealth distribution viewed as fair by all the future generations in country $A$ : as we can see, that level increases over time. The offspring of a very egalitarian generation, though agreeing with their parent's view of the world of their times, by critically assessing the productive participation by their peers, will become increasingly more tolerant of wealth disparities. 

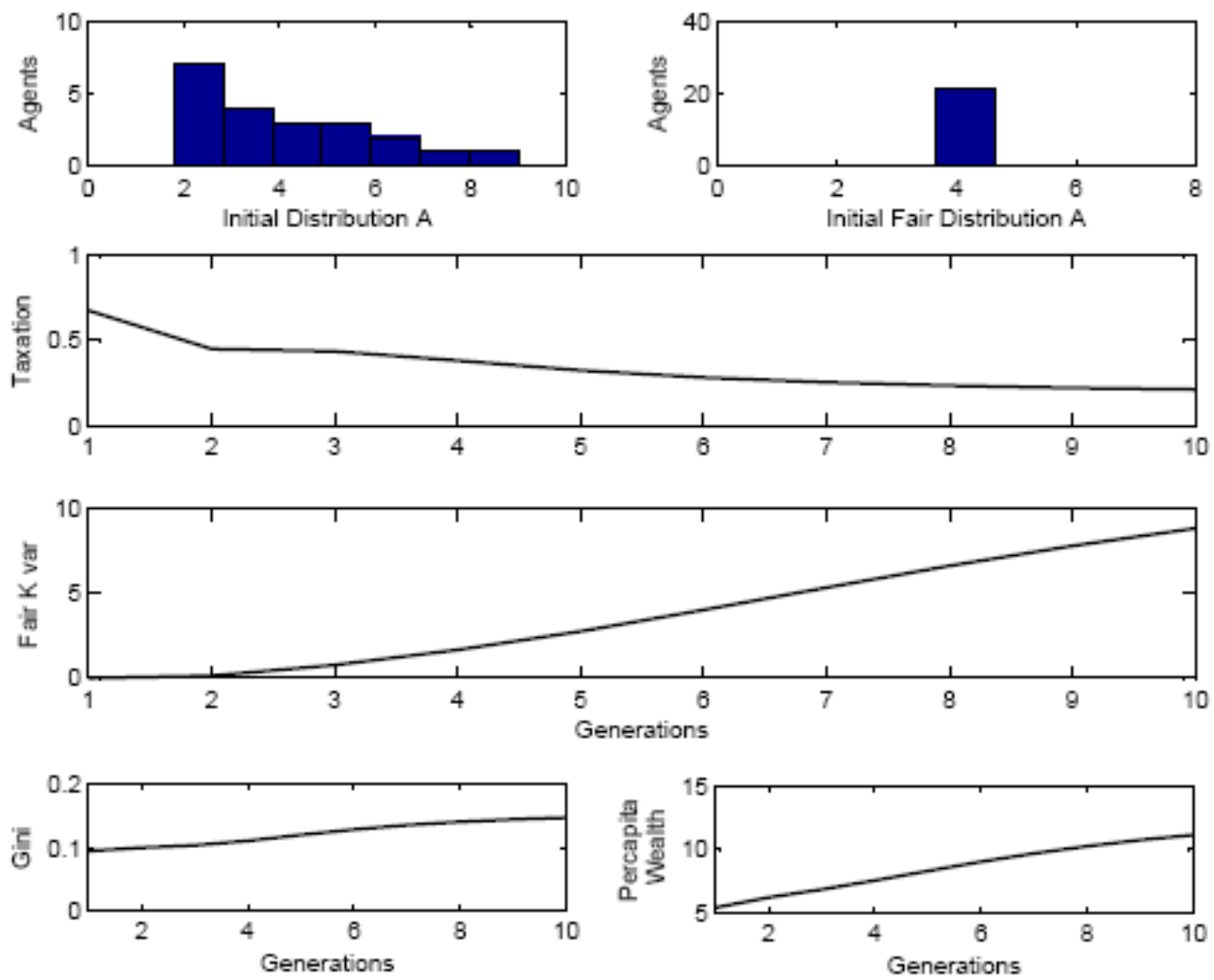

Figure 1b

In summary, differences in ideas of social justice of a generation can persist for several generations. These ideas evolve slowly together with the evolution of the economy.

Note that for some parameter values we have multiple steady states. In such cases, the strictly egalitarian ideology prevailing in an initial generation in country $A$ can support very strong redistributive policies. High enough taxation would then discourage individual efforts so dramatically that a large part of individual's wealths would be the result of luck, and hence deemed very unfair. Therefore, the next generation would decide to tax a lot as well. In the long run the unfairness/redistribution/poverty trap would never be corrected, and the two economies would differ in everything, with country $B$ richer, but more 
unequal, than country $A$.

\subsection{Initial Inequality}

In a dynamic version of the Meltzer and Richard's (1981) model, higher initial inequality leads to more redistribution, higher taxes and lower capital accumulation and growth. This is the prediction of Alesina and Rodrik (1994), and Persson and Tabellini (1994). It is straightforward to reproduce this result in our framework. Imagine two countries with different initial level of inequality and in which there is no difference across countries about how much of the initial inequality is fair or not, and $\gamma$ is the same in the two countries. Then there would be higher taxes and more redistribution in the country with more inequality. Simulations along those lines are available from the authors.

However, Perotti (1996) first and then others have questioned empirically, the positive correlation relationship between more pre tax inequality and redistribution. $^{14}$ A negative correlation between initial inequality and redistribution can be easily obtained in our model. Imagine two countries, with different levels of initial inequality, but suppose that in the country with more inequality the latter is considered fair, while in the other country the inequality, even though lower, is considered unfair. Imagine also that in the second country the parameter $\gamma$ is especially high, namely in this country citizens are especially averse to inequality (unfairly induced). One can easily generate examples in which more inequality leads to less redistribution. One needs different ratios of fair versus unfair inequality and/or different weights given in the two countries to the cost of inequality and unfairness.

Another reason why inequality may not lead to more but less redistribution is the case when more inequality leads to a stronger influence of rich voters in the political equilibrium. ${ }^{15}$ So far, in our probabilistic voting framework, we have worked under the assumption of common values of $\varphi_{i}$ for all $i \in[0,1]$. However, this may not be the case, as different voters are differently reactive to the parties' announcement of different policies, based on the relative importance they give to ideological and personal characteristics associated with the different parties. Our model allows all possible assumptions about the individual political biases. When the rich have larger political influence and when wealth is correlated to more political influence redistribution is lower. This will of course imply higher growth and a larger Gini. All the simulations regarding these cases are available upon request.

\subsection{Different views about what is fair}

In this section we analyze the effects of different views about fairness, by comparing three countries.

\footnotetext{
${ }^{14}$ See also Bénabou (1996) for a survey.

${ }^{15}$ See Baremboim and Karabarbounis (2009) for some cross country empirical evidence on this point and Mc Charty Poole and Rosenthal (2008) for a discussion on the United States.
} 
1) Country $A$ is our benchmark case and we assume $\gamma=0.1$. Thus individuals in country $A$ have preferences described by eq.s (5) and (6);

2) In country $B \gamma=0$. This is the traditional Meltzer-Richard case in which redistribution occurs only for selfish reasons, namely the poor want to tax the rich and there is no distinction between fair and unfair inequality;

3) In Country $C$, individuals are averse to inequality per se, as measured by the variance of end-of-life post-tax wealth, $w_{i t}$, that is individuals in country $C$ have preferences for redistribution in which:

$$
\Omega_{t}^{C}=\operatorname{var}\left(w_{i t}\right) .
$$

In Figure 2 we compare the performance of economies with everything else equal, but the three different concepts of social justice. 

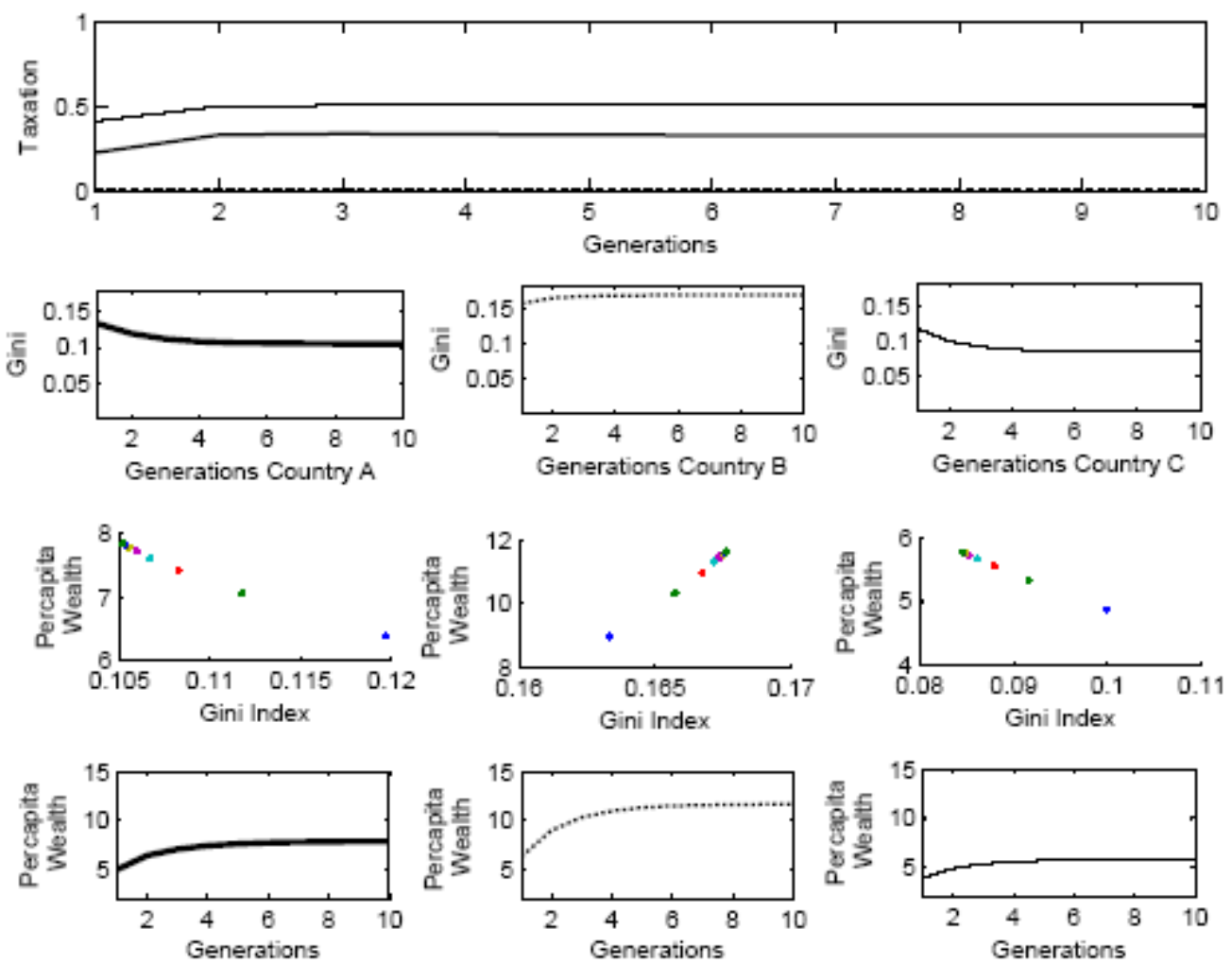

Figure 2

As in the figure, country $B$ immediately starts with no redistribution (the tax rate always stays on the horizontal axis: $\tau_{t}^{B}=0$, for all $t(=1,2, \ldots)$, whereas countries $A$ and $C$ approach steady states with positive redistribution. The reason why the usual inequality-redistribution channel is not at work in country $B$ is probabilistic party loyalty, along with the symmetric party bias among the citizens. However, positive taxation emerges also in the $\gamma=0$ case as soon as we introduce asymmetric policy bias. Thus the fact that in this experiment $\tau_{t}^{B}=0$ is just a special case, but in any case country $B$ would have lower taxes than countries $A$ and $C$. In our example, country $B$ will become persistently richer than country $A$, which in turn gets richer than country $C$. In this example, country $A$ 's tax rate tends to $32.63 \%$, while country $C$ 's tax 
rate tends to $50.38 \%$.

\subsection{A Poverty Trap}

By poverty trap we mean a situation in which a country does not manage to exit poverty because the policies induced by poverty itself are not growth enhancing. Consider two economies sharing the same distribution of luck, willingness to work, and inner abilities, but different initial levels and distributions of capital and fair capital. Assume that one economy, $A$, starts from a low and unequal level of capital endowment; while the other, $B$, from a high and similarly unequal level of capital endowment, as shown in Figure 3a:
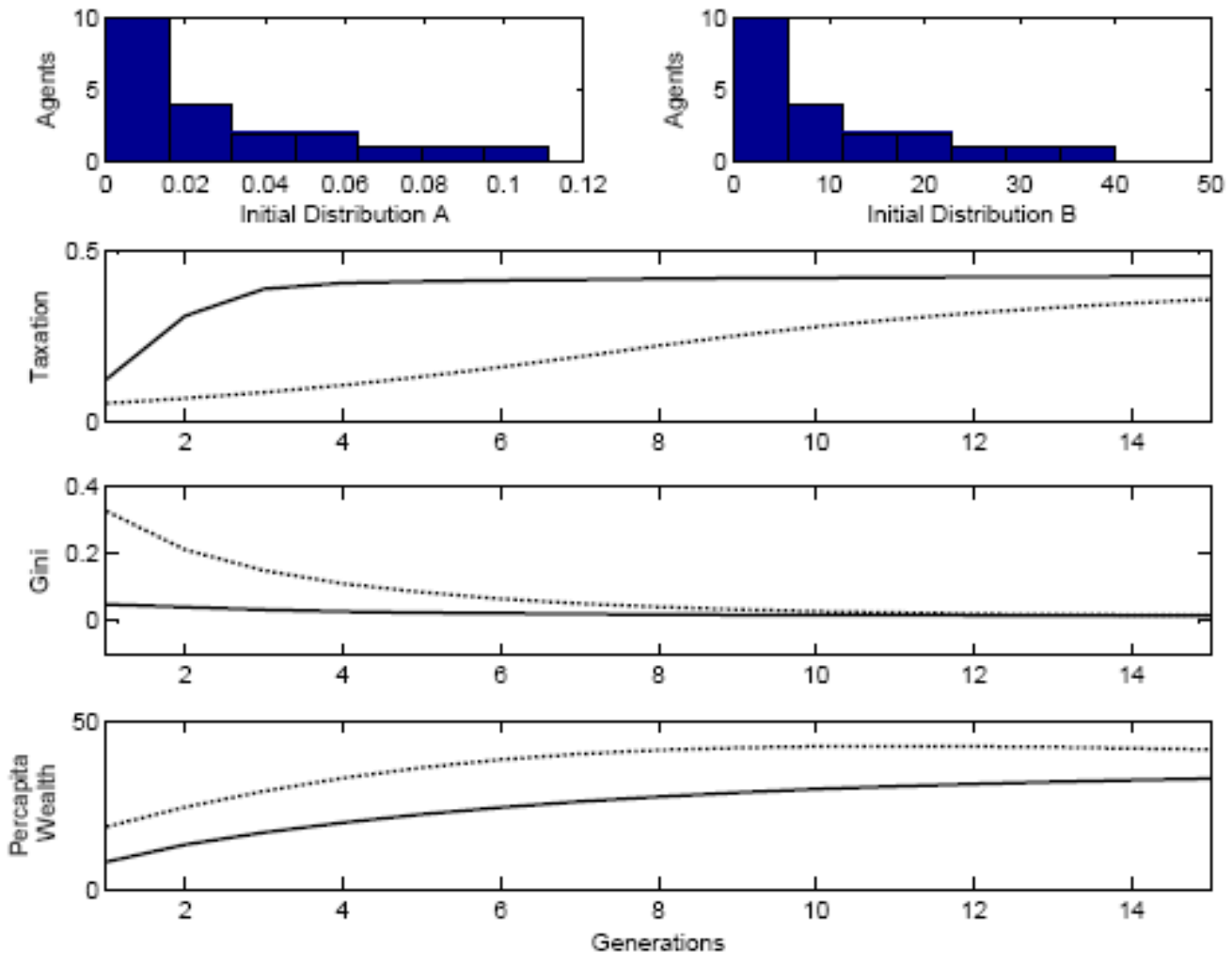

Figure 3a . Solid Line: Country A. Dashed Line: Country B 
In both countries the initial level of fair wealth is set equal to the actual initial wealth distribution ${ }^{16}$. This example is representative of cases in which, when the country is poor, the luck component represent a larger share of realized wealth, and this induces the voters to prefer a high level of taxation. The poorer country starts with a higher redistribution, while the rich country simply increases redistribution at a lower pace. This in turn disincentives efforts and capital accumulation, thereby causing lower aggregate wealth accumulation. The country is cast for long into a poverty trap; with high taxes and low wealth.

Eventually, after some generations, in the previous figure, the poorer country starts slowly to accumulate more capital and to vote for reducing tax rates. Growth starts to increase and the poorer country tends to catch up with the other country's level of capital and taxation. The evolution of the concept of fairness plays a very important role also in this case. As the generations pass by, the agents in the poorer country start to consider more and more fair the differences in the capital accumulation deriving from the abilities and the efforts. In this way taxation decreases and the capital accumulation can finally take off.

However, by slightly altering the parameters, we can provide examples in which the poverty trap is more extreme, as shown in Figure $3 \mathrm{~b}$ below ${ }^{17}$ :

\footnotetext{
${ }^{16}$ This is to avoid the consequences of imposing unexplained (hence arbitrary) fairness motivated initial redistributive policies. Of course, over the generations the fair and unfair wealth distributions will differentiate, thereby endogenously inducing unfairness driven redistributive decisions.

${ }^{17}$ To generate this kind of examples, it suffices to slightly increase the value of $\gamma$ and to slightly increase the dispersion of the luck distribution.
} 

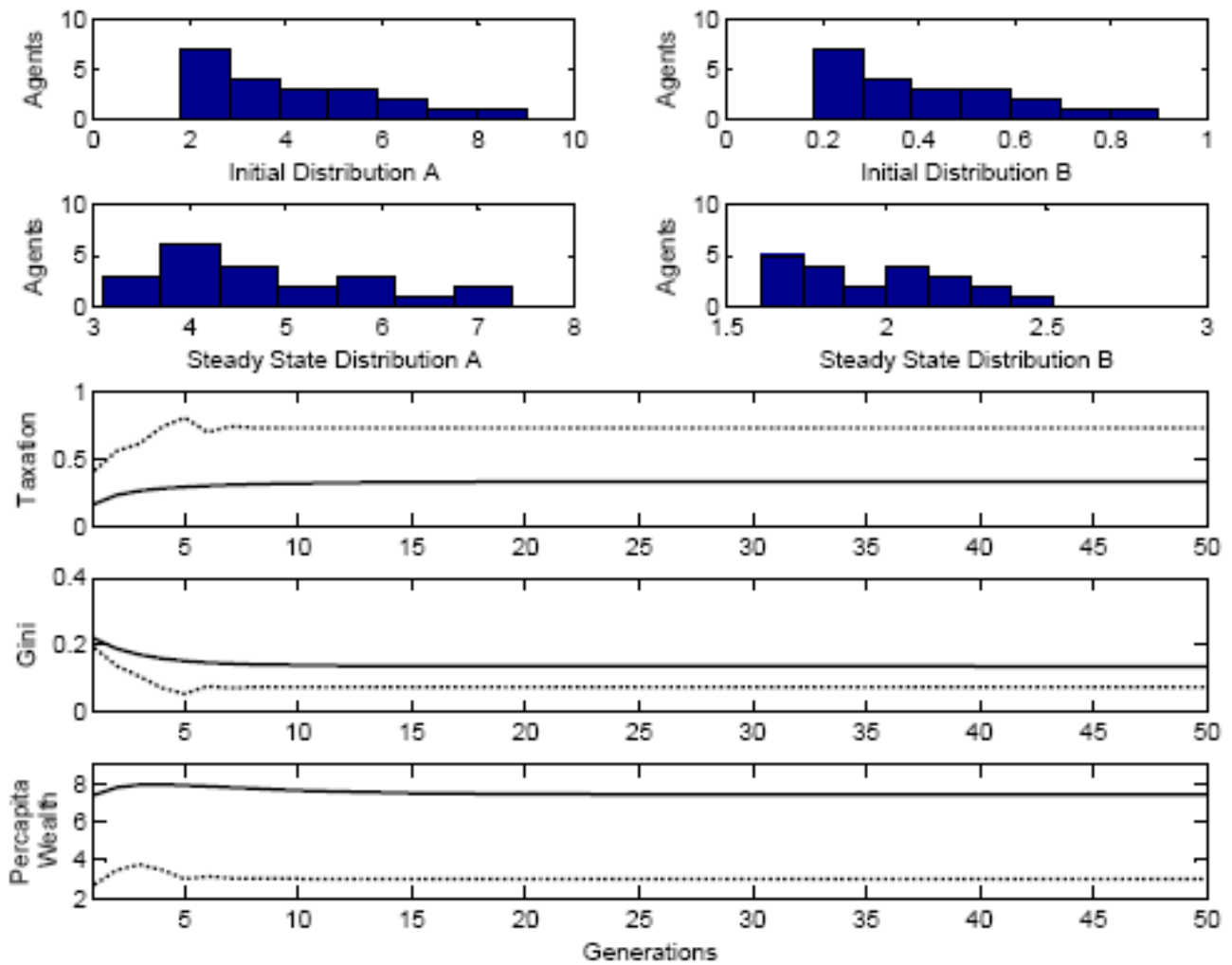

Figure 3b . Solid Line: Country A. Dashed Line: Country B

In this example, we have assumed that country $B$ starts ten times poorer than country $A$, while both countries believed their own initial wealth distribution to be fair (to avoid adding interfering ingredients). In country $B$, sheer poverty implies that a large part of people end-of-life wealth is due to luck, which causes the election of very highly redistributive policy platforms. Once in place, they will discourage individual efforts, thereby causing luck to play a central role in individual enrichment; this in turn reinforces the perception of unfairness in the wealth distribution, and corroborates drastically redistributive policies, thus perpetuating the poverty trap. Country $B$ will never catch up with country $A$ : it will rather converge to a different steady state wealth distribution, characterized by more poverty, more taxation, and less inequality. 
It should be noted that very poor countries often do not have a well developed tax structure. Often in these countries redistributive policies take even more distorting forms often associated with corruption and in many cases ethnic politics. All the factors would make matters even worse and increase the chances of a poverty trap. Di Tella and Mc Culloch (2007) discuss reason why free market capitalist institutions may be fragile in developing countries precisely because the wealth inequality generated in those countries are (perhaps correctly so) perceived as generated by corruption and connections rather than abilities and effort.

\subsection{Shocks to Wealth Distribution}

Inequality is generally a slow moving variable, but a few large events can affect it quite much for a few years. Wars have been one example of such events, which have reduced wealth disparities by much. (Piketty and Saez, 2003). The financial crisis of 2007-2009 may also have deep effects on inequality, both on its actual measure and the perception of fairness of certain types of riches accumulated in financial markets, pre-crisis CEO and bankers' bonuses, etc. What are the effects on fiscal policy and the evolution of inequality of these shocks? The next two sections show that opposite effects on policy may arise, depending on how the wealthy classes' losses are judged by the voters.

\subsubsection{Shocks which equalize capital holdings}

We can trace the effect of a shock in our stylized economy, by assuming that at some date - say, generation 4 - in country $B$ - otherwise identical to country $A$ there is an unexpected shock that cuts all initial capital levels at a ceiling equal to $70 \%$ of the highest inherited capital level. We maintain the assumption of initial distribution viewed as fair. Figure 4 shows what would happen without the shock (country $A$ ) and with the shock (case $B$ ): 

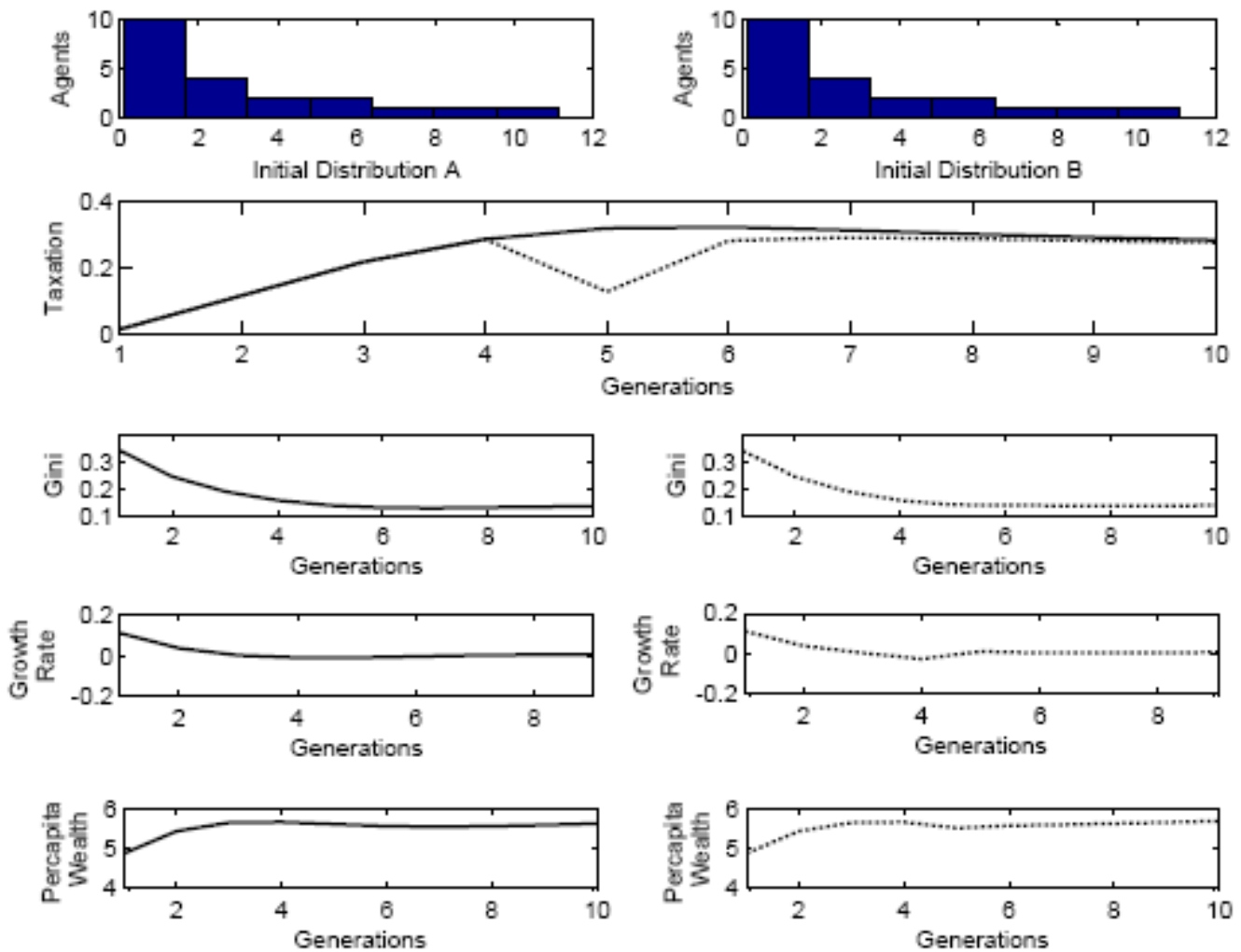

Figure 4

Since the shock is equalizing wealth levels, there is a temporary negative effect on the equilibrium tax rate due to the fairness motive: "too rich" wealth levels would be curtailed by the shock while "too poor" wealths are relieved by tax reduction. The reduction in redistribution is voted as soon as the shock arrives and allows the economy to witness only a relatively weak negative temporary effect on income and on inequality. The economy will re-absorb them completely within few generations. Moreover, the lower level of inequality following the shock has relatively persistent negative effects on voted taxation and positive effects on capital accumulation. In fact, in the figure's example, the 10th generation's (6 generations after the shock) tax rate in country $A$ is $28.54 \%$ while in country $B$ is $27.79 \%$; similarly, country $B$ 's percapita wealth is 
$1.19 \%$ higher than country $A$ 's percapita wealth.

\subsubsection{Shocks which equalize individuals' productivities}

Suppose now that the top individual abilities are curtailed: we will assume that for one generation $\tilde{t}$ (in the example of the figure $\tilde{t}=4$ ) we have $\delta_{i \tilde{t}}=\min \left\{\delta_{i}\right.$, $\left.0.60 \max _{j \in[0,1]} \delta_{j}\right\}$. That is, we set a temporary ceiling for the abilities/stamina equal to $60 \%$ of their highest level in normal times. Lower abilities are left unchanged. Figure 5 shows the effects:
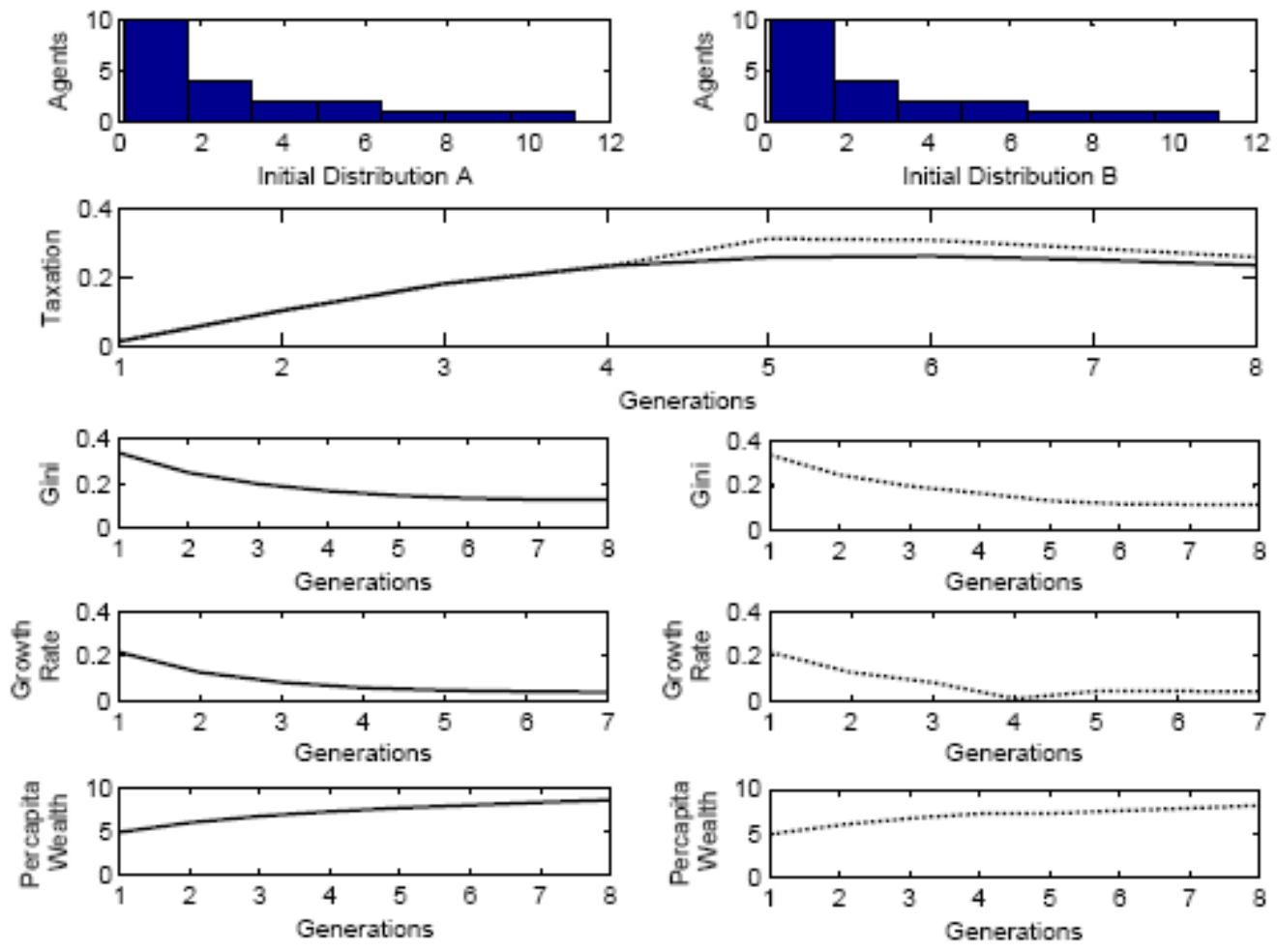

Figure 5 
As we can notice in the figure, in country $A$ there is no crisis, while in country $B$ the shock arrives. As a consequence there is a relatively strong fall in the growth rate of country $B$. Unlike in figure 4 , here the crisis is followed by an increase in redistribution: despite the crisis' equalizing power, country $B$ 's voters choose more redistribution and higher tax rates. Why so? Fairness considerations tilt fiscal policy in favour of higher redistribution: if it is not creativity or hard work that pays off the rich so much, then the relative importance of unjustified "luck" (which may include all sorts of non-work related sources of extra gains $/ \operatorname{losses}^{18}$ ) increases. Therefore, the perception of unfairness in the creation of wealth would be mounting, thereby inducing voters to increase redistribution and exacerbate the economic consequences of the crisis. As shown in the example illustrated by Figure 5, in the generation after the crisis (generation 5), country $A$ 's tax rate is $25.97 \%$ while country $B$ 's tax rate is $31.5 \%$. Moreover, as the figure shows, these effects could be persistent, which is not too surprising once realized that higher tax rates introduce additional departures from fairness, to be corrected by the next generation, and so on.

One of the effects of the financial crisis of 2007-09 might have been to convince (rightly or wrongly) that much of the wealth built in the period leading up to the crisis were due to "luck" . The comparison of the financial market to "a Las Vegas casino", where, in fact, you win mostly by luck, were common. Our model would predict that despite the fact that the crisis itself might have reduced inequality, it would increase the political support for more redistribution precisely for a changed perception of what is "fair" wealth. The political emphasis on salary caps for managers and bankers is supportive of this interpretation.

\subsubsection{Non-Persistent "Luck"}

After reading the discussion in the previous section, 3.5.2, one may wonder if our policy result hinges on the extreme assumption of perfectly persistent intra-family "luck" $\eta_{i t}=\eta_{i}$ for all $i \in[0,1]$ and all $t=0,1,2, \ldots$ : if luck was not persistent, perhaps a negative shock on the most able individuals would not entail a higher than usual weight of luck in income and wealth. To check the robustness of this - along with other - result, we have run simulations by assuming that for every generation $t$ the inter-family luck vector at birth, $\eta_{i t}$, is independently drawn from a zero mean uniform distribution. This eliminates luck persistence completely, thereby allowing a substantial degree of upwards and downwards social mobility. Interestingly, all simulations we have performed reproduce the regularity observed in the simpler deterministic case $\eta_{i t}=\eta_{i}$ : after the ability-equalizing shock, the winning tax rate is always higher than in the absence of the shock. A representative example is shown in the following Figure 5b:

\footnotetext{
${ }^{18}$ Outrageously high pensions by bailed-out bank managers, etc.
} 

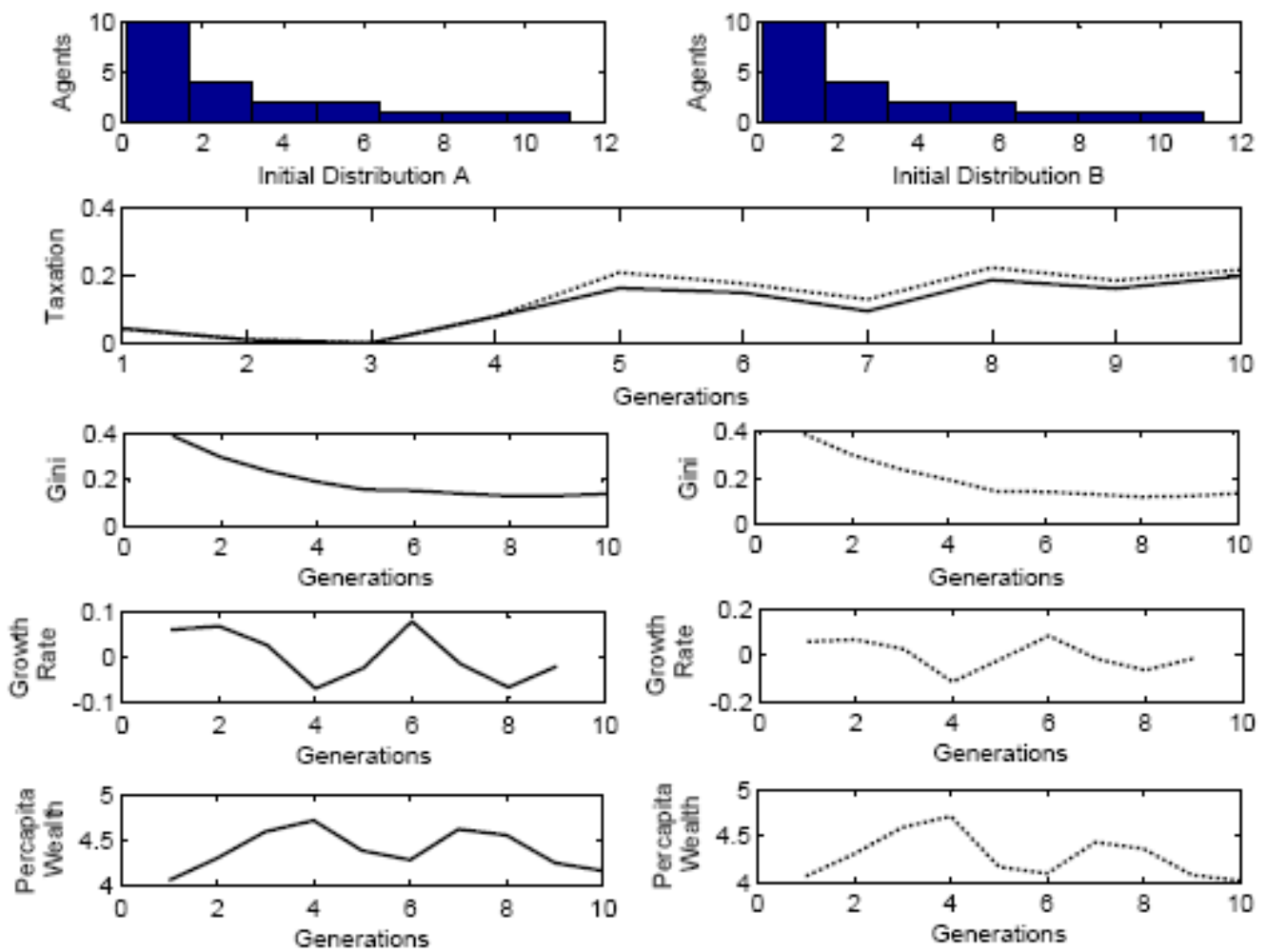

Figure 5b

As seen from the figure, due to the stochasticity of the "luck" distribution, here fluctuations have been endogenously generated. We remark that, in our simulations, the realizations of random luck vector, $\eta_{i t}$, generated is the same in both scenarios $A$ and $B$, which explains why their cyclicity is correlated; however, country $B$, represented by dashed lines, is subjected to a one time ability ceiling (of $60 \%$ of the top ability, as in previous section 3.5.2) in period 4 , whereas country $A$ is not. In all cases we have tried, right after the negative shock on the top abilities, the country $B$ voters are more inclined to redistribute than the voters of country $A$ : the reason is that at the aggregate level, in the generation hit by the shock, luck matters relatively more than ability in explaining individual riches. Country $B$ 's higher than usual taxation in one generation 
implies higher distortions (i.e. less effort and lower production), hence higher relative weights of luck, thereby inducing persistence in the propensity to vote for higher tax rates. Despite fluctuations led by changing luck distribution, the effects of a one time ability-equalizing crisis take some time to be fully reabsorbed, with the two countries eventually converging to the same stochastic process.

If the parameters are such that multiple (stochastic) steady states can arise, the long term effect of a temporary financial crisis could be a persistent "soak the rich" effect, as shown in the following example:
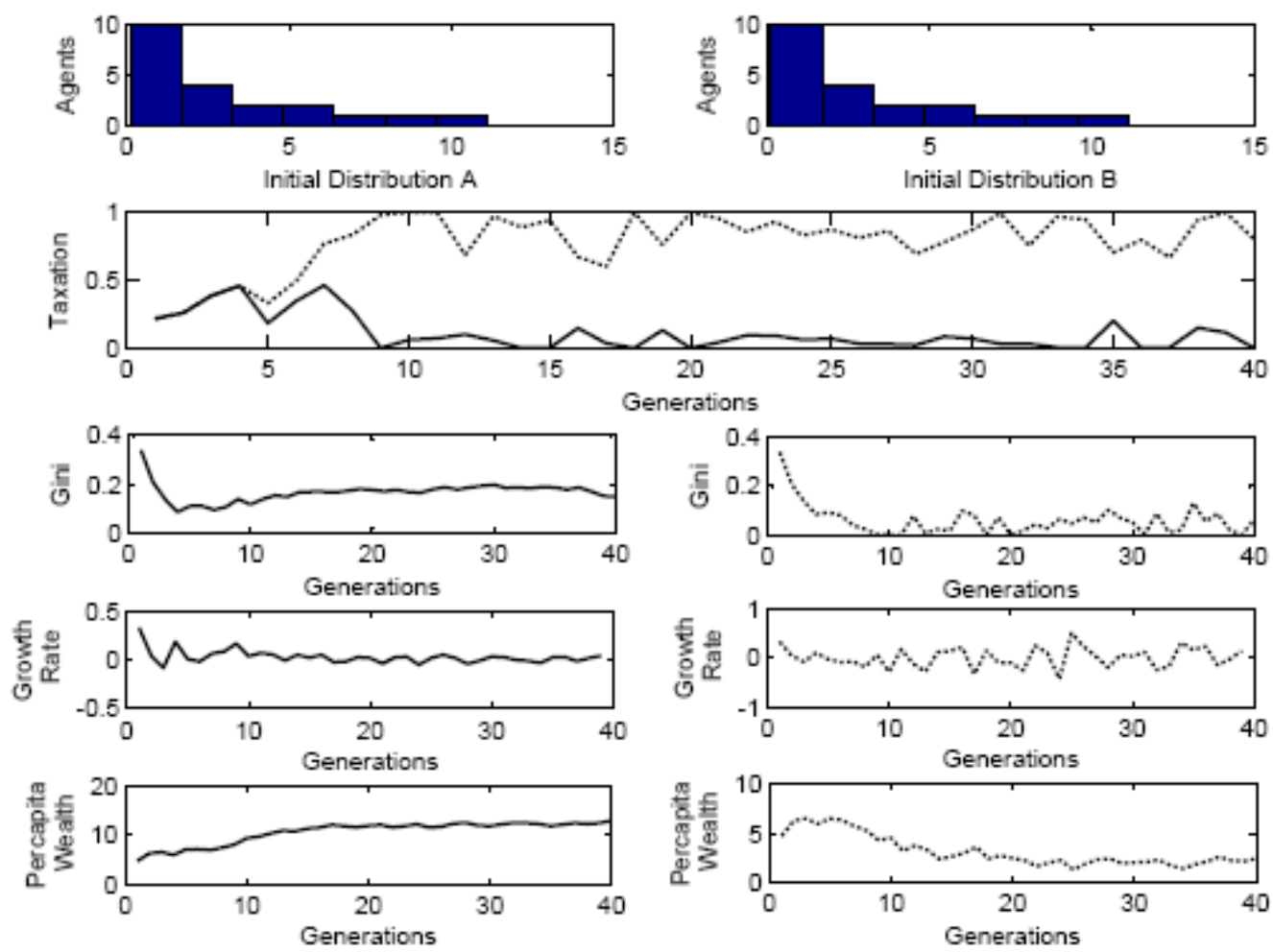

Figure 5c 
In Figure 5c, despite the same realization of the luck vector, the arrival in country $B$ of a temporary negative shock to the top abilities triggers drastically different economic performances: while country $A$ follows a trajectory characterized by very low taxation and very high percapita wealth, country $B$ becomes characterized by the periodic election of extremely high - even expropriatory tax rates, accompanied by much lower percapita wealths, and exhibiting much higher growth volatility than country $A$.

\section{Conclusions}

In this paper, we have shown how the evolution of the political ideology regarding the fairness of the constellation of income and wealth in society can generate economic and political persistence in inequality, redistribution, and growth. According to our simple framework, ideology does not entail cognitive distortions of reality, but it shapes the moral judgement on what wealth distribution would be fair, as well as it internalizes into people's preferences how strongly the distance between the current wealth distribution and the fair one makes people unhappy. Our model is consistent with a variety of observations about the relationship between inequality, redistribution, and persistence of poverty which could not be explained with more standard models of redistributive policies.

Rather than reviewing again our results, it is worth discussing possible extensions to this framework. Probably the most interesting one would be to extend the policy set of tax and transfer schemes. A particularly relevant one comes to mind, namely inheritance taxation. This model with its emphasis on fairness seems ideal to address issues of social justice like equalizing initial conditions versus redistribution. That is, an alternative view about social justice could be that everybody should start from the same initial conditions, and therefore inherited wealth, no matter how generated, should be heavily taxed to equalize everybody at birth. This of course would have implications on savings, capital accumulation, and the amount of bequest, but the structure provided by this model seems ideal to study this set of issues. Another generalization would be to allow non linear tax structures to permit for more progressive income and wealth taxation.

\section{Appendix}

Lemma 1. In pairwise majority voting, there will exist a unique equilibrium in which the two parties will select the same policy variable, $\tau_{t}^{L}=\tau_{t}^{R} \equiv \tau_{t}^{*}$, given by

$$
\tau_{t}^{*}=\arg \max _{\tau_{t} \in[0,1]} \int_{0}^{1} \varphi_{i} \hat{U}_{i t}\left(\tau_{t}\right) d i .
$$


Proof. In fact, individual $i$ of generation $t$ will vote for party $R$ if $\hat{U}_{i t}\left(\tau_{t}^{R}\right)>$ $\hat{U}_{i t}\left(\tau_{t}^{L}\right)+\sigma_{i t}+\varepsilon_{t}$, that is if $\sigma_{i t}<\hat{U}_{i t}\left(\tau_{t}^{R}\right)-\hat{U}_{i t}\left(\tau_{t}^{L}\right)-\varepsilon_{t}$. Given our assumption on $\sigma_{i t}$, this event happens with probability $\left[\hat{U}_{i t}\left(\tau_{t}^{R}\right)-\hat{U}_{i t}\left(\tau_{t}^{L}\right)-\varepsilon_{t}\right] \varphi_{i}+\frac{1}{2}$. Aggregating over all individuals and using the law of large numbers, the fraction of votes that goes to party $R$ is: $\pi_{R}=\int_{0}^{1}\left\{\left[\hat{U}_{i t}\left(\tau_{t}^{R}\right)-\hat{U}_{i t}\left(\tau_{t}^{L}\right)-\varepsilon_{t}\right] \varphi_{i}+\frac{1}{2}\right\} d i=$ $\int_{0}^{1}\left[\hat{U}_{i t}\left(\tau_{t}^{R}\right)-\hat{U}_{i t}\left(\tau_{t}^{L}\right)\right] \varphi_{i} d i-\varphi \varepsilon_{t}+\frac{1}{2}$, where $\varphi \equiv \int_{0}^{1} \varphi_{i} d i$ is the average of the individual ideological densities. Party $R$ wins if $\pi_{R}>\frac{1}{2}$, which happens if and only if $\varepsilon_{t}<\frac{\int_{0}^{1}\left[\hat{U}_{i t}\left(\tau_{t}^{R}\right)-\hat{U}_{i t}\left(\tau_{t}^{D}\right)\right] \varphi_{i} d i}{\varphi}$. From our assumptions on $\varepsilon_{t}$, this happens with probability $\left(\frac{\int_{0}^{1}\left[\hat{U}_{i t}\left(\tau_{t}^{R}\right)-\hat{U}_{i t}\left(\tau_{t}^{D}\right)\right] \varphi_{i} d i}{\varphi}-\left[-\frac{1}{2 \psi}\right]\right) \psi=\psi \frac{\int_{0}^{1}\left[\hat{U}_{i t}\left(\tau_{t}^{R}\right)-\hat{U}_{i t}\left(\tau_{t}^{D}\right)\right] \varphi_{i} d i}{\varphi}+$ $\frac{1}{2} \equiv p_{R}$. Party $R$ therefore chooses $\tau_{t}^{*}=\arg \max p_{R}=\arg \max _{\tau_{t}^{R}} \int_{0}^{1} \hat{U}_{i t}\left(\tau_{t}^{R}\right) \varphi_{i} d i$. Swapping notations, party $D$ chooses $\tau_{t}^{*}=\arg \max p_{D}=\arg \max _{\tau_{t}^{D}} \int_{0}^{1} \hat{U}_{i t}\left(\tau_{t}^{D}\right) \varphi_{i} d i$. By Weierstrass theorem a maximum certainly exists. Moreover, it is generically unique. Q.E.D.

Lemma2. Let us assume that the distribution of abilities and luck are such that $\inf \left\{A_{i}^{2} \beta_{i}: i \in[0,1]\right\}>-\inf \left\{\eta_{i}: i \in[0,1]\right\}$. Then $w_{i t} \geq 0$ for all $i \in$ $[0,1]$, and $t=1,2, \ldots$, for every non-negative initial capital vector $k_{i 0}, i \in[0,1]$, and for every tax rate sequence $\tau_{t} \in[0,1]$.

Proof.

First notice that the above stated condition implies:

$$
\int_{0}^{1} A_{j}^{2} \beta_{j} d j>-\inf \left\{\eta_{i}: i \in[0,1]\right\} \equiv\left|\eta^{\mathrm{inf}}\right| .
$$

Let us consider the worst possible scenario, in which $k_{i t-1}=0$ for all $i \in[0,1]$ : if we are able to prove that $k_{i t}=\alpha w_{i t} \geq 0$ in this case, then $k_{i t} \geq 0$ will hold in all other cases.

From the definition of end-of-life post-tax wealth, optimal effort choice,and government transfer, it easily follows that

$$
w_{i t}=\left(1-\tau_{t}\right) z_{i t}+G_{t}=\left(1-\tau_{t}\right)^{2} A_{i}^{2} \beta_{i}+\left(1-\tau_{t}\right) \eta_{i}+\tau_{t}\left(1-\tau_{t}\right) \int_{0}^{1} A_{j}^{2} \beta_{j} d j,
$$

which expresses $w_{i t}$ as a quadratic function of $\tau_{t}$. Hence, $w_{i t}=0$ if and only if 
$\tau_{t}=1$ and

$$
\tau_{t}=-\frac{\eta_{i}+A_{i}^{2} \beta_{i}}{\int_{0}^{1} A_{j}^{2} \beta_{j} d j-A_{i}^{2} \beta_{i}} .
$$

Let us first focus on the $\tau_{t}=1$ root. Since in $\tau_{t}=1, w_{i t}=0$, as $\tau_{t}$ becomes lower than 1 , we need to make sure that $w_{i t}$ does not immediately become negative: that is we want $w_{i t}$ to be locally a decreasing function of $\tau_{t}$. Taking the derivative of $w_{i t}$ with respect to $\tau_{t}$ we get:

$$
\frac{d w_{i t}}{d \tau_{t}}=-2\left(1-\tau_{t}\right) A_{i}^{2} \beta_{i}-\eta_{i}+\left(1-\tau_{t}\right) \int_{0}^{1} A_{j}^{2} \beta_{j} d j-\tau_{t} \int_{0}^{1} A_{j}^{2} \beta_{j} d j<0
$$

if and only if:

$$
\eta_{i}>-2\left(1-\tau_{t}\right) A_{i}^{2} \beta_{i}+\left(1-2 \tau_{t}\right) \int_{0}^{1} A_{j}^{2} \beta_{j} d j .
$$

Notice that if $\tau_{t}=1$ inequality (18) holds true if

$$
\eta_{i}>-\int_{0}^{1} A_{j}^{2} \beta_{j} d j
$$

holds, which is a consequence of inequality (14).Clearly, this guarantees only that $w_{i t}>0$ for $\tau_{t}$ slightly less than 1 .

Setting $\tau_{t}=0$ in (15), it becomes:

$$
w_{i t}=A_{i}^{2} \beta_{i}+\eta_{i},
$$

which is positive if $A_{i}^{2} \beta_{i}>-\eta_{i}$, which holds under the condition in the statement. Hence, being wealth (15) quadratic in $\tau_{t}$, the second root of $w_{i t}=0$ given by eq. (16) - has to be negative if the corresponding parabola is concave or larger than 1 if it is convex ${ }^{19}$. In both cases, $w_{i t}>0$ for all $\tau_{t} \in[0,1]$. QED

\footnotetext{
${ }^{19}$ Simple graphing shows that any parabola $y=a x^{2}+b x+c$ sloping down at $x=1$ and positive at $x=0$, will be positive for all $0 \leq x<1$.
} 


\section{References}

Alesina, A. and G.M. Angeletos, (2005a), "Fairness and Redistribution," American Economic Review, vol. 95(4), pp. 960-80.

Alesina, A. and G.M. Angeletos, (2005b), "Corruption, Inequality, and Fairness," Journal of Monetary Economics, vol. 52(7), pp. 1227-44.

Alesina, A. and E.L. Glaeser, (2004), "Fighting Poverty in the US and Europe: A World of Differences," New York: Oxford University Press.

Alesina, A. and P. Giuliano, (2010), "Preferences for Redistribution," forthcoming in A. Bisin and J. Benhabib eds. Handbook of Social Economics, North Holland Amsterdam.

Alesina, A. and E. La Ferrara, (2005), "Preferences for Redistribution in the Land of Opportunities," Journal of Public Economics, vol. 89(5-6), pp. 897-931.

Alesina A., R. Di Tella, and R. McCulloch, (2004), "Inequality and Happiness: are Europeans and Americans Different? " Journal of Public Economics, vol. 88 (9-10), pp. 2009-2042.

Alesina A. and D. Rodrik, (1994), "Distributive Politics and Economic Growth," The Quarterly Journal of Economics, vol. 109(2), pp. 465-490.

Barenboim I. and L. Karabarbounis, (2009), "One dollar one vote," Unpublished.

Bénabou, R., (1996), "Inequality and Growth," in Ben S. Bernanke and J. J. Rotemberg, eds., National Bureau of Economic Research Macro Annual, vol. 11, pp. 11-74.

Bénabou, R. and J. Tirole, (2006), "Beliefs in a Just World and Redistributive Politics," Quarterly Journal of Economics, vol. 121(2), pp. 699-746.

Bénabou, R., (2008), "Joseph Schumpeter Lecture Ideology," Journal of the European Economic Association, vol. 6(2-3), pp. 321-352.

Di Tella, R. and R. MacCulloch, (2007). "Why Doesn't Capitalism Flow to Poor Countries?," NBER Working Papers 13164.

Fong, C., (2001), "Social Preferences, Self-Interest, and the Demand for Redistribution," Journal of Public Economics, vol. 82(2), pp. 225-246.

Heckman, J.J., (2008), "Schools, Skills, and Synapses," Economic Inquiry, Vol. 46(3), 289-324.

Lindbeck A. and J. W. Weibull, (1987), "Balanced-Budget Redistribution as the Outcome of Political Competition," Public Choice, vol. 52(3), pp. 273-297.

Lindbeck A. and J. W. Weibull, (1993), "A Model of Political Equilibrium in a Representative Democracy," Journal of Public Economics, vol. 51(2), pp. 195-209.

Mc Carthy N. K. Pooler and H. Rosenthal (2008) Polarized America MIT Press Cambridge Mass

Meltzer, A.H. and S. Richard, (1981), "A Rational Theory of the Size of Government," Journal of Political Economy, vol. 89(5), pp. 914-27.

Perotti, R., (1993), "Political Equilibrium, Income Distribution, and Growth," Review of Economic Studies, vol. 60(4), pp. 755-776. 
Perotti, R.,(1996), "Growth, Income Distribution and Democracy: What the Data Say," Journal of Economic Growth, vol. 1(2), pp.149-87.

Persson, T. and G. Tabellini, (1994), "Is inequality harmful for growth?" American Economic Review, vol. 84(3), pp. 600-621.

Persson, T. and G. Tabellini, (2000), "Political Economics: Explaining Economic Policy," Cambridge, MA: MIT Press.

Piketty, T., (1995), "Social Mobility and Redistributive Politics," The Quarterly Journal of Economics, vol. 110(3), pp. 551-584.

Piketty T. and E. Saez, (2003), "Income inequality in the United States, 1913-1998," Quarterly Journal of Economics, vol. 118(1), pp. 1-39. 